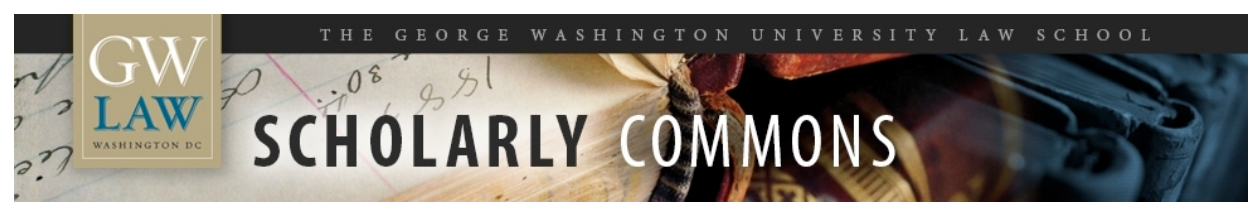

\title{
Cultural Cognition of the Risks and Benefits of Nanotechnology
}

Donald Braman

George Washington University Law School, dbraman@law.gwu.edu

Dan M. Kahan

Paul Slovic

John Gastil

Geoffrey L. Cohen

Follow this and additional works at: https://scholarship.law.gwu.edu/faculty_publications

Part of the Law Commons

\section{Recommended Citation}

Donald Braman et. al., Cultural Cognition of the Risks and Benefits of Nanotechnology, 4 Nature Nanotechnology 87 (2009)

This Article is brought to you for free and open access by the Faculty Scholarship at Scholarly Commons. It has been accepted for inclusion in GW Law Faculty Publications \& Other Works by an authorized administrator of Scholarly Commons. For more information, please contact spagel@law.gwu.edu. 
print version: Cultural Cognition of the Risks and Benefits of Nanotechnology. Nature Nanotechnology, 4(2), 87-91.

\title{
Cultural Cognition of the Risks and Benefits of Nanotechnology
}

\author{
Dan M. Kahan ${ }^{1 *}$ \\ John Gastil ${ }^{4}$
}

Donald Braman ${ }^{2}$

Paul Slovic 3

Geoffrey Cohen 5

${ }^{1}$ Yale Law School, PO Box 208215, 127 Wall St., New Haven, CT 06520, USA.

* email: dan.kahan@yale.edu

2 The George Washington University Law School, 2000 H Street, NW, Washington, DC 20052, USA.

${ }^{3}$ Decision Research 1201 Oak Street, Suite 200 Eugene, Oregon 97401, USA.

${ }^{4}$ Department of Communication, University of Washington, Box 353740 Seattle, WA 98195, USA.

5 Department of Psychology, University of Colorado, Boulder, Muenzinger Psychology Bldg., Boulder, Colorado 80309, USA. 


\begin{abstract}
We conducted an experimental public opinion study of the effect of balanced information on nanotechnology risk-benefit perceptions. The study found that subjects did not react in a uniform, much less a uniformly positive manner, but rather polarized along lines consistent with cultural predispositions toward technological risk generally.
\end{abstract}


How is public opinion toward nanotechnology likely to evolve? The "familiarity hypothesis" holds that support for nanotechnology will likely grow as awareness of it expands. The basis of this conjecture is opinion polling, which finds that few members of the public claim to know much nanotechnology, but that those who say they do are substantially more likely to believe its benefits outweigh its risks ${ }^{1,2,3,4}$. Some researchers, however, have avoided endorsing the familiarity hypothesis, stressing that cognitive heuristics and biases could create anxiety as the public learns more about this novel science ${ }^{5,6}$. We conducted an experimental study aimed at determining how members of the public would react to balanced information about nanotechnology risks and benefits. Finding no support for the familiarity hypothesis, the study instead yielded strong evidence that public attitudes are likely to be shaped by psychological dynamics associated with cultural cognition.

"Cultural cognition" refers to the tendency of persons to base their factual beliefs about the risks and benefits of a putatively dangerous activity on their cultural appraisals of these activities $^{7,8}$. From a psychological point of view it is easier to believe that behavior one finds noble is socially beneficial, and that behavior one finds debased is dangerous, than vice versa ${ }^{9,10}$. Persons who are "individualistic" and "hierarchical" in their cultural worldviews tend to dismiss claims of environmental risk, for example, because acknowledging such hazards would threaten the autonomy of markets and the authority of social elites. Persons who hold "egalitarian" and "communitarian" worldviews, on the other hand, take environmental risks seriously because they believe unregulated markets are a source of inequality and, therefore, harmful to society ${ }^{11,12}$. Consistent with this dynamic, researchers have found evidence that people of opposing cultural outlooks polarize on various environmental and technological risks - from nuclear power ${ }^{13}$ to global warming ${ }^{14}$ to genetically modified foods to mad cow disease ${ }^{15}$. 
The cultural cognition hypothesis holds that these same patterns are likely to emerge as members of the public come to learn more about nanotechnology. That is, rather than adopt uniformly positive attitudes, as the familiarity hypothesis suggests, members of public who hold relatively egalitarian and communitarian worldviews will perceive its risks to be greater, and its benefits smaller, than will persons who hold relatively hierarchal and individualistic worldviews.

We designed a public opinion study to test the familiarity and cultural cognition hypotheses. The study reflected an experimental design aimed at detecting causal links, if any, between information exposure and attitude formation. We divided a diverse, national on-line sample of 1,850 Americans into two groups. Those in the "no-information condition" were told nothing about nanotechnology other than that it is a scientific process for producing and manipulating very small particles. Those in the "information-exposed condition," in contrast, were furnished with two paragraphs of equal length and comparable information content, one identifying possible benefits of nanotechnology, the other possible risks. We then compared the two groups' perceptions of nanotechnology risks and benefits to see what effect information exposure had.

Like most members of the American public ${ }^{1,2}$, our study subjects reported being relatively unfamiliar with nanotechnology. The vast majority—over $80 \%$-reported having heard either "just a little" (28\%) or "nothing at all" (54\%) about it. Only 4\% reported having heard "a lot" about nanotechnology before the study, and 14\% reported having heard "some," an amount in between "just a little" and "a lot." Among subjects in the no-information condition, familiarity with nanotechnology was positively correlated with the perception that nanotechnology's benefits outweigh its risks $\left(r_{s}=.38, p<.001\right)$, a finding likewise consistent with previous public opinion studies ${ }^{1,2,3,4}$.

Information exposure had no discernable main effect on subjects' perceptions of nanotechnology risks and benefits. The mean assessment on a four-point risk-benefit measure 
(NANORISK) for subjects in the information-exposed condition $(M=2.37, s d=1.03)$ was virtually identical to the mean assessment for subjects in the no-information condition $(M=2.34$, sd $=$ $0.99)$.

To assesses whether the impact of information exposure varied based on either familiarity with nanotechnology or cultural worldviews, we performed a multivariate regression analysis. The dependent variable for the analysis was whether subjects perceived the benefits of nanotechnology to be greater than its risks or vice versa. Independent variables included cultural worldview measures, the interaction of those worldviews, the degree of self-reported knowledge, and appropriate interactions of these variables with the experimental condition to which subjects were assigned. This analysis (Supplemental Information, Table S1) can be used to determine how information exposure influences individuals either conditional on their cultural worldviews holding their level of familiarity constant; or conditional on their level of familiarity holding their cultural worldviews constant. 


\begin{tabular}{lc} 
Predictor & Effect \\
\hline Information & 6.95 \\
& $(4.00)$ \\
Self-reported Familiarity (NANOKNOW) & $-0.85^{*}$ \\
& $(0.08)$ \\
Individualism (v. Communitarianism) & $1.79^{*}$ \\
& $(0.81)$ \\
Hierarchy (v. Egalitarianism) & $2.14^{*}$ \\
& $(0.86)$ \\
Hierarchy x Individualism & $-0.77^{*}$ \\
& $(0.31)$ \\
Information x Self-reported Familiarity (NANOKNOW) & $0.33^{*}$ \\
& $(0.16)$ \\
Information x Hierarchy & $-3.18^{*}$ \\
& $(1.57)$ \\
Information x Individualism & -2.63 \\
& $(1.45)$ \\
Information x Hierarchy x Individualism & $1.11^{*}$ \\
& $(0.55)$ \\
\hline Log Likelihood & $-1,045.09$ \\
Prob $>$ Chi ${ }^{2}$ & 0.00 \\
Pseudo ${ }^{2}$ (McKelvey -Zavoina) & 0.14 \\
\hline
\end{tabular}

Table S1. Logistic Regression Analysis: Risk-Benefit Perceptions Across Experimental Conditions. $N=$ 1,672. The dependent variable is a dichotomous measure: Nanotechnology Benefit $>$ Risk (0) vs. Nanotechnology Risk > Benefit (1). Independent variable effects are expressed in log-odds (logit) coefficients. $*$ denotes significant at $\mathrm{p} \leq .05$. Standard errors are in parentheses.

Results are illustrated in Figure 1. Holding cultural-worldviews constant (at the sample mean), information exposure does not have a significant effect on the likelihood that either a subject who is relatively unfamiliar with nanotechnology or one who is relatively familiar with it will perceive the benefits of nanotechnology to be greater than its benefits.

In contrast, information exposure has a relatively large and statistically significant impact on subjects defined with reference to their cultural worldviews. In the no-information condition, subjects whose cultural worldviews are moderately hierarchical and individualistic, on the one hand, and subjects whose worldviews are moderately egalitarian and communitarian, on the other, are equally likely (61\%) to see the benefits of nanotechnology as outweighing its risks if we hold their level of self-reported knowledge constant (at the sample mean). In the information- 
exposed condition, however, the likelihood that hierarchical individualists will perceive benefits as greater than risks grows by $25 \%$, while the likelihood that egalitarian communitarians will do so shrinks by $38 \%$ - opening up a $63 \%$ gap ( $86 \%$ to $23 \%$ ) between them.

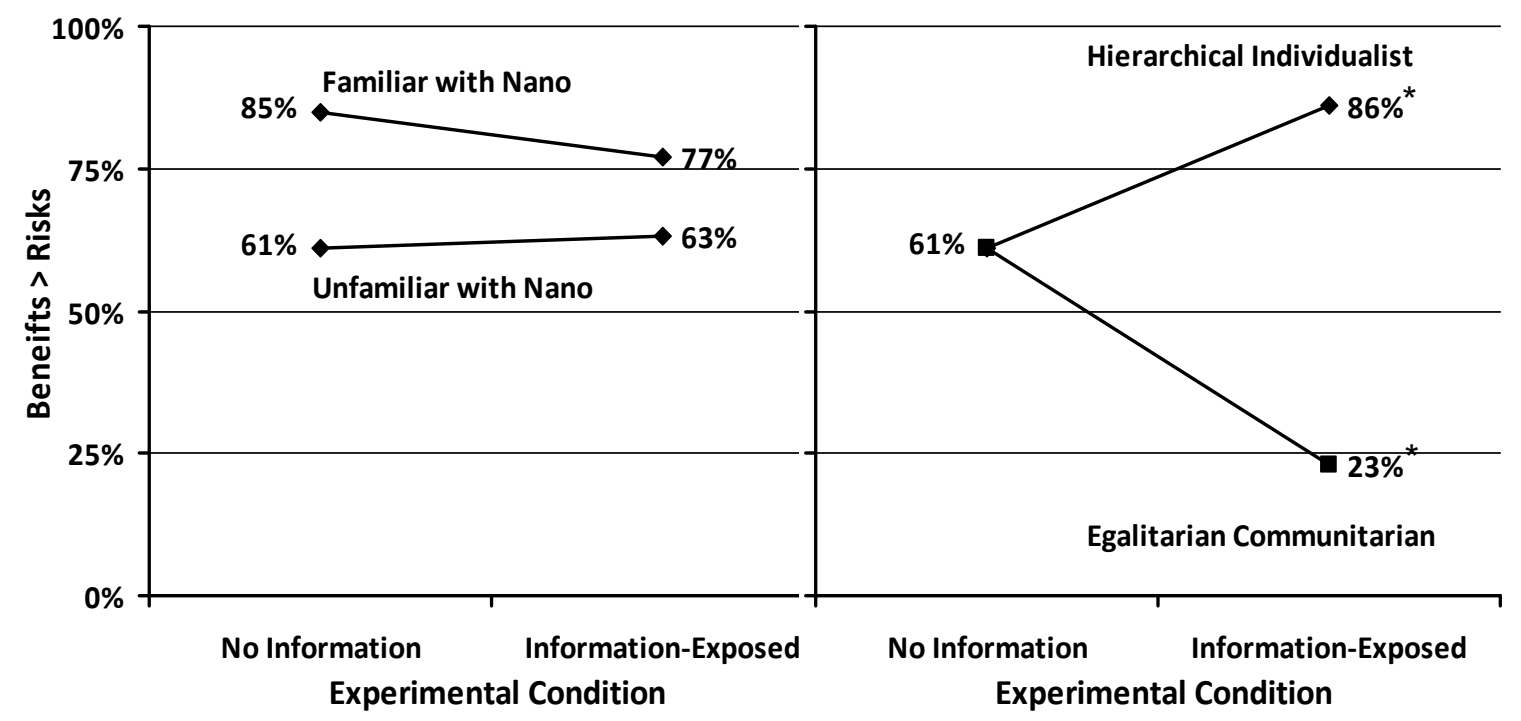

Figure 1. Effect of Information on Risk-Benefit Perceptions of Subjects Defined by Familiarity and Cultural Worldviews. $N=1,672 .{ }^{*}$ denotes change in likelihood across conditions significant at $p \leq .05$. Likelihoods of response are derived by statistical simulation ${ }^{16}$ from the logistic regression analysis reported in Supplemental Information, Table S1. The left-hand simulation displays likelihoods of response for Benefits $>$ Risks in the noinformation and information-exposed conditions when cultural worldviews are controlled for (set to their means) and when self-reported knowledge levels are set to values between "nothing at all" and a "a little" (unfamiliar), on the one hand, and "some" and "a lot" (familiar), on the other. The right-hand simulation displays the likelihoods of response across conditions when knowledge level is controlled for (set to its mean) and the culture variables are set at values that reflect the worldviews of modestly hierarchical and individualistic subjects, on the one hand, and modestly egalitarian and communitarian ones, on the other.

These results support the cultural cognition hypothesis but not the familiarity hypothesis. Our subjects did not react uniformly, much less in a uniformly positive manner, when exposed to information. Instead, they reacted divergently, in a manner consistent with their opposing cultural predispositions toward technological risk generally. This finding displays the signature of biased assimilation and polarization - the tendency of persons to conform information to their predispositions and thus to become more, not less, divided when exposed to balanced informa$\operatorname{tion}^{17}$. 
This result naturally begs the question why those who report greater familiarity with nanotechnology - in the no-information condition of our study and in previous opinion surveys - tend to see the risks of nanotechnology as great and the risks as small. One possibility is selection bias. The relatively small portion of the population who say they have heard either a modest amount or a great deal about nanotechnology are obviously different from the vast majority who have heard little or noting. The same set of forces that creates their unique motivation to learn about nanotechnology might also be uniquely disposing these persons to form positive views about it.

The study also yielded two other findings that reinforce this conclusion. First, we found that the subjects (in both conditions) who reported being relatively familiar with nanotechnology — the $18 \%$ who claimed to have heard either "a lot" or "some" about it—were not only less likely to perceive the risks of nanotechnology as greater than its benefits. They were also less likely than nanotechnology-unfamiliar subjects to be concerned with all manner of riskwhether from genetically modified foods, mad cow disease, nuclear power generation, or the internet (Figure 2). Obviously, it is not plausible to think that their familiarity with nanotechnology is the reason these persons are relatively unworried about these other risks. Instead, it is more sensible to think that there is something else that is causing people who are generally skeptical of environmental and technological risks to learn more about (or at least claim they have learned more about) nanotechnology. 


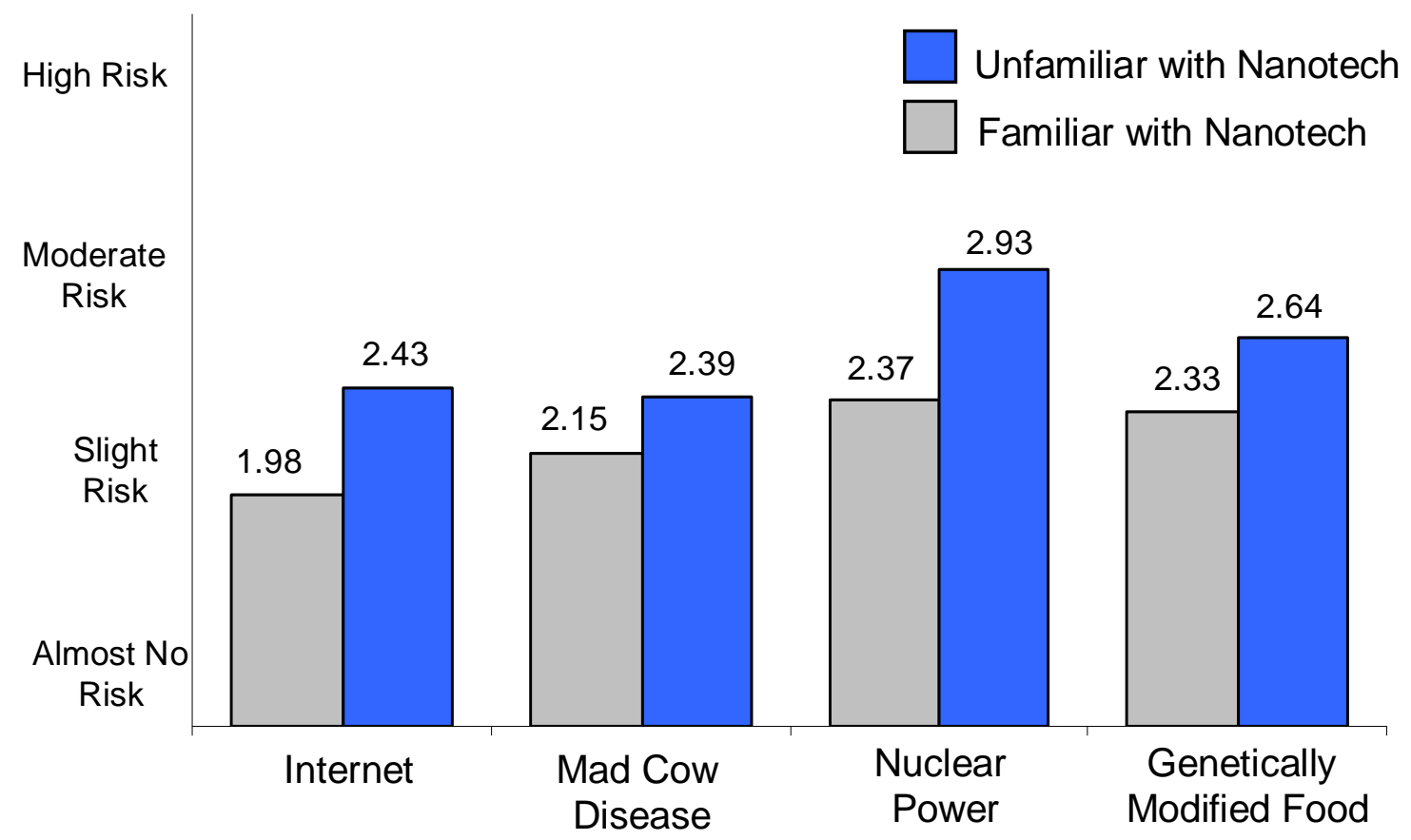

Figure 2. Other Risk Perceptions of Persons Familiar and Unfamiliar with Nanotechnology.. $n=1,820$ to 1,830 . Risk variables are 4-pt measures of "risk to people in American Society" posed by indicated risk. Canonical correlation between familiarity and the risk measures significant at $p \leq .01$. Differences between group means all significant at $p \leq .01$.

The second finding sheds some light on what that influence — or set of influences—might be. Regressing self-reported familiarity with nanotechnology on various individual characteristics revealed that being simultaneously hierarchical and individualistic predicted greater familiarity with nanotechnology (Supplemental Information, Table S2 and Figure S1). Because these worldviews generally dispose individuals to be skeptical about technological risks ${ }^{13,14,15,18}$, it is no surprise that experimental subjects of this sort reacted positively when exposed to balanced information on nanotechnology. By the same token, it is no surprise that egalitarian and communitarians, who are less likely in the normal course to learn about nanotechnology, react less favorably when such information is brought to their attention. 


\begin{tabular}{lc} 
Predictor & Effect \\
\hline Male & $0.94^{*}$ \\
White (vs. Black) & $(0.14)$ \\
Other Minority (vs. Black) & 0.48 \\
& $(0.27)$ \\
Education & $0.60^{*}$ \\
& $(0.30)$ \\
Age & $0.29^{*}$ \\
& $(0.04)$ \\
Household Income & $-0.01^{*}$ \\
& $(0.00)$ \\
Republican (vs. Democrat) & -0.02 \\
& $(0.02)$ \\
Independent (vs. Democrat) & 0.07 \\
Conservative (vs. Liberal) & $(0.17)$ \\
& -0.21 \\
Hierarchy (vs. Egalitarianism) & $(0.32)$ \\
& 0.02 \\
Individualism (vs. Communitarianism) & $(0.06)$ \\
Hierarchy x Individualism & $-3.10^{*}$ \\
& $(0.71)$ \\
\hline Log Likelihood & $-2.01^{*}$ \\
Prob $>$ Chi2 & $(0.66)$ \\
\hline & $0.99^{*}$ \\
& $(0.25)$ \\
\hline
\end{tabular}

Table S2. Logistic Regression Analysis: Self-Reported Familiarity with Nanotechnology. $N=1,785$. The dependent variable is a dichotomous measure of self-reported knowledge of nanotechnology based on NANOKNOW ("Nothing at all" and "a little" = 0; "Some" and "A lot" = 1). Independent variable effects are expressed in ordered log odds (logit) coefficients. * denotes significant at $p \leq .05$. Standard errors in parentheses.

In total, the study findings suggest a particular model of how cultural predispositions and information about nanotechnology work (Figure 4). In the model, such predispositions both affect the likelihood of information exposure and moderate how information affects risk-benefit perceptions. People who have a pro-technology cultural orientation are thus more likely to become exposed to information about nanotechnology and to draw positive inferences from what they discover. Individuals who lack that predisposition, in contrast, are less likely to become ex- 
posed to information, and when they do become exposed to it are significantly more likely to react negatively.

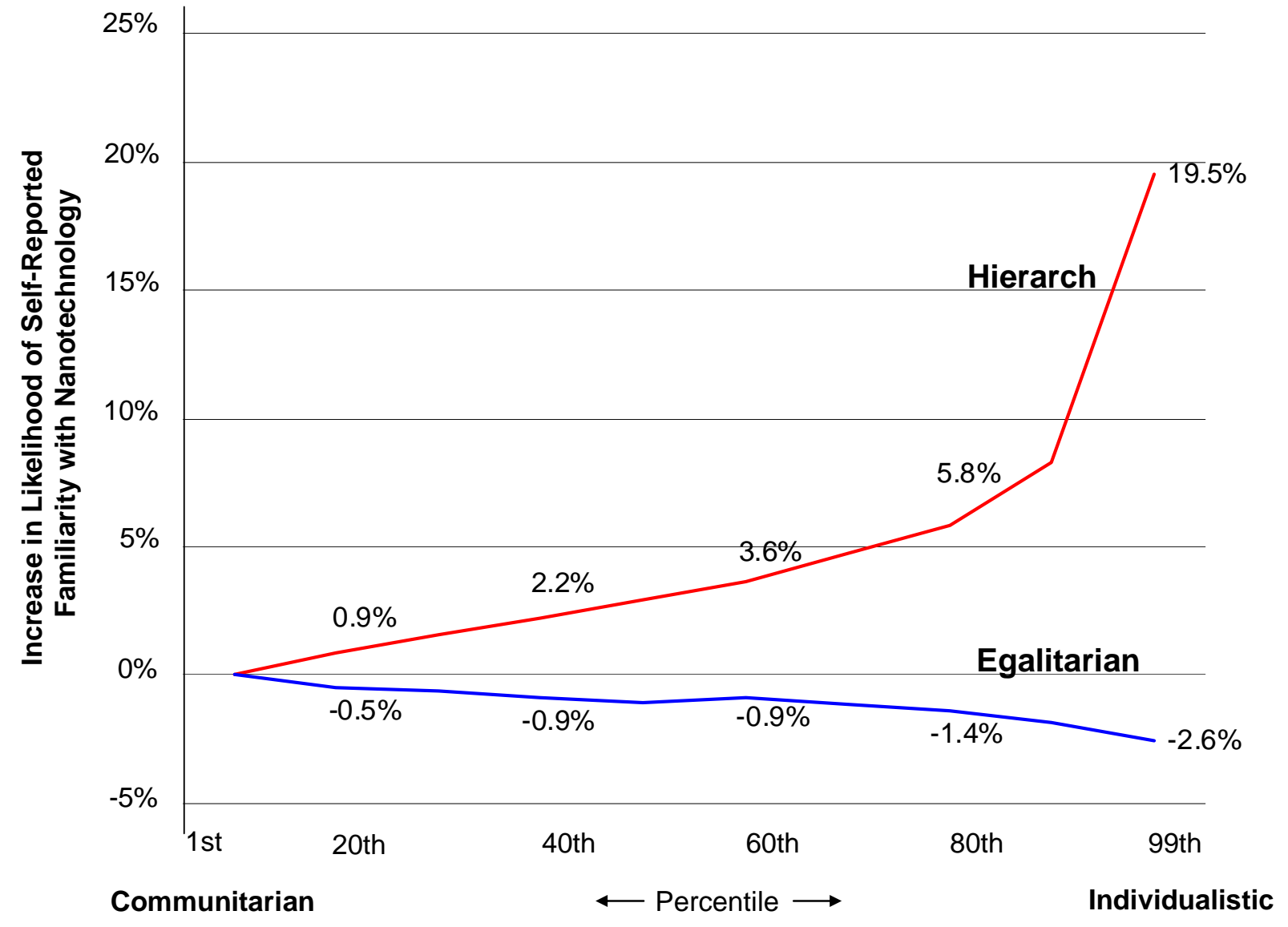

Figure S3. Predicted Increase in Likelihood Of Self-Reported Familiarity With Nanotechnology As Individualism Increases. $N=1,785$. Likelihoods are derived by statistical simulation ${ }^{16}$ from the logistic regression analysis reported in Table S2. The curves for "Hierarch" and "Egalitarian" show the impact of increasing degrees of individualism when the value for Hierarchy in the regression model is set one standard deviation from the mean toward the hierarchy and egalitarianism ends of the HierarchyEgalitarianism scale, respectively. Values for all other predictors are controlled for (by being set to their sample means).

Our study reinforces the conclusions of other researchers who have cautioned against assuming that enlightened public opinion will spontaneously emerge from accumulating scientific information on the risks and benefits of nanotechnology $y^{5,19}$. Indeed, because individuals in the real world are likely to select information in a biased fashion that matches their cultural and political dispositions ${ }^{20}$, one might anticipate even more extreme polarization outside the psychol- 
ogy lab than we observed in it when we exposed our subjects to a small bit of balanced information.

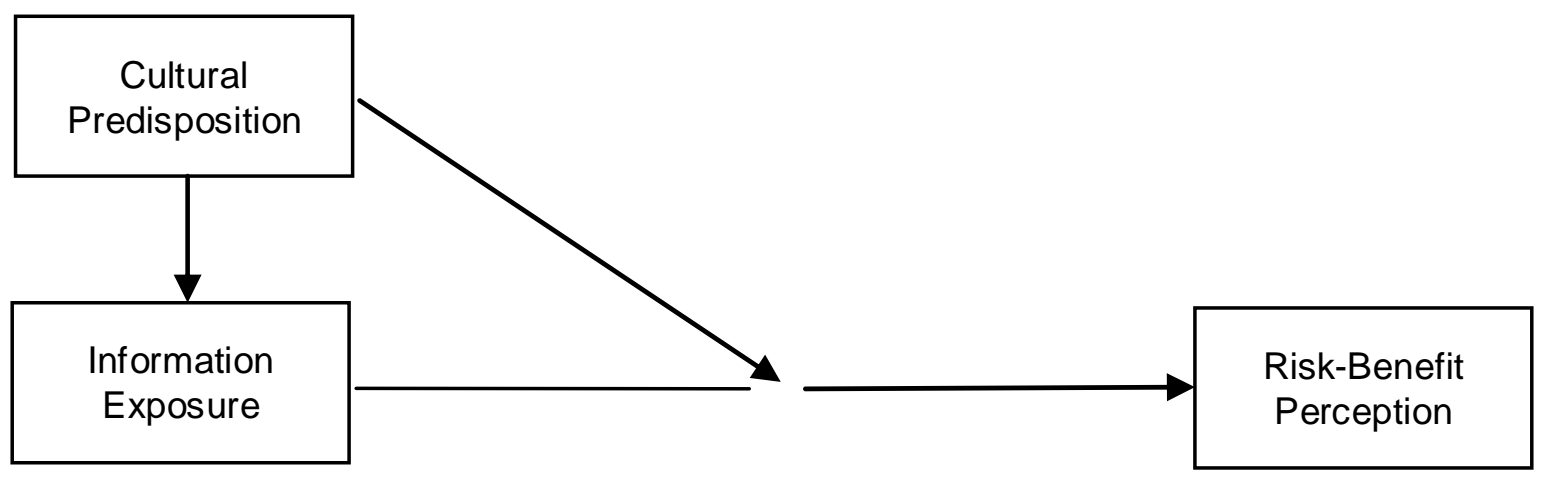

Figure 4. Relationships Between Cultural Predispositions, Information Exposure, and Risk-Benefit Perceptions. The study results suggest that cultural worldviews influence perceptions of the risks and benefits of nanotechnology both by influencing how likely subjects were to be exposed to information (or report being exposed to information) about nanotechnology and by determining what effect - positive or negative - they gave to that information.

At the same time, nothing in our study suggests that cultural polarization over nanotechnology is inevitable. Social psychology is making important advances in identifying techniques for framing information on controversial policy issues in a manner that makes it possible for persons of diverse values to derive the same factual information from $\mathrm{it}^{21}$. With further study, it is likely that these techniques can be used to guide risk communication and thus enhance democratic deliberations on risk-regulation policy — on nanotechnology ${ }^{6}$ and on other issues ${ }^{22}$.

The practical lesson of our study, then, is that those who favor informed public deliberations on nanotechnology should be neither sanguine nor bleak. Instead they should be psychologically realistic. If they are, they will see the urgent need for additional efforts to develop risk communication strategies that make it possible for culturally diverse citizens to converge on policies that promote their common interests.

\section{Methods}


The sample consisted of 1,862 adults recruited by Knowledge Networks to be members of a probability-based on-line panel representative of the United States population. There has been considerable study of how probability-based on-line sampling, which is becoming increasingly common in scholarly public opinion research, performs relative to random-digit-dial telephone and other survey methods ${ }^{23,24,25}$. More information on the sampling methods of Knowledge Networks can be found at http://www.knowledgenetworks.com/ganp/index.html. Subjects participated in the study using Knowledge Networks' on-line facilities in December 2006.

In addition to standard demographic data, the study collected data on subjects' cultural values. Measures, adapted from previous studies of cultural cognition and the cultural theory of risk $^{13,18,26}$, assessed subjects' values with two scales, "Individualism-Communitarianism" $(\alpha=$ $.83)$ and "Hierarchy-Egalitarianism" $(\alpha=.81)$. Each scale was designed to measures a separate dimension of the "group-grid" worldview typology proposed by Mary Douglas. ${ }^{27}$ In the regression-based simulation (Figure 1), the culture variables for "hierarchical, individualists" were set at values one standard deviation from the mean toward the hierarchy and individualist ends of the those scales; the culture variables for "egalitarian communitarian" subjects were set at values one standard deviation from the mean toward the egalitarian and communitarian ends of those scales.

Subjects perceptions of nanotechnology were also solicited. All subjects responded to a self-reported knowledge item (NANOKNOW) used in previous studies ${ }^{1,2,3,4}$ that stated, "How much have you heard about nanotechnology before today?," and permitted the responses, "Nothing at All," "Just a Little," "Some," “A Lot." For certain analysis (Table S2 and Figures 1 and 2), subjects who answered "some" or "a lot" were deemed "familiar" with nanotechnology, and those who answered "nothing at all" or "just a little" were deemed "unfamiliar." All subjects also responded to a four-point item (NANOBENEFIT), which required them to indicate whether they 
believed "(1) the risks of nanotechnology will greatly outweigh its benefits," (2) the risks of nanotechnology will slightly outweigh its benefits," "(3) the benefits of nanotechnology will slightly outweigh its risks" or "(4) the benefits of nanotechnology will greatly outweigh its risks." A reverse-coded item (NANORISK) was used to compute the mean scores for subjects in both conditions. In the multivariate logistic regression analysis (Table S1), responses to this item were collapsed into a dichotomous "Benefit > Risk" (0) and "Risk > Benefit" (1) measure.

Before responding to NANOBENEFIT, all subjects read this introductory statement:

Now we would like to know what you think about nanotechnology. Nanotechnology is the ability to measure, see, predict and make things on the extremely small scale of atoms and molecules. Materials created with nanotechnology can often be made to exhibit very different physical, chemical, and biological properties than their normal size counterparts.

Subjects assigned to the information-exposed condition were also asked to read the following two paragraphs (the order of which was rotated) before responding to NANOBENEFIT:

The potential benefits of nanotechnology include the use of nanomaterials in products to make them stronger, lighter and more effective. Some examples are food containers that kill bacteria, stain-resistant clothing, high performance sporting goods, faster, smaller computers, and more effective skincare products and sunscreens. Nanotechnology also has the potential to provide new and better ways to treat disease, clean up the environment, enhance national security, and provide cheaper energy.

While there has not been conclusive research on the potential risks of nanotechnology, there are concerns that some of the same properties that make nanomaterials useful might make them harmful. It is thought that some nanomaterials may be harmful to humans if they are breathed in and might cause harm to the environment. There are also concerns that invisible, nanotechnologybased monitoring devices could pose a threat to national security and personal privacy. 
All subjects, before responding to the items relating to nanotechnology, also indicated their perceptions of a variety of other risks on a four-point scale that permitted them to characterize a set of activities or states of affairs as presenting "Almost No Risk," "Slight Risk," "Moderate Risk," or "High Risk." This item, too, was patterned after one used in previous riskperception studies ${ }^{28,29}$. Because few subjects ever report seeing "no risk," "Almost No Risk" has been shown more accurately to separate out the subjects who are the most risk-skeptical from those are the next most risk-skeptical.

The complete study instrument is available on request from the corresponding author. 


\section{Author Contributions}

All authors participated in the design of the study, in analysis of the results, and in drafting and revision of the paper. 


\section{Acknowledgements}

Research for this paper was supported by the National Science Foundation, Grant SES 0621840; by the Project on Emerging Nanotechnologies Woodrow Wilson International Center for Scholars; and by the Oscar Ruebhausen Fund at Yale Law School. We thank Ellen Peters for advice on the study design, and Robert MacCoun and two anonymous referees for valuable comments on earlier drafts. The authors have no affiliation with the Wilson International Center for Scholars, nor do the authors have commercial relationships, or conflicts of interest, that affected this research. No corporation influenced the design or execution of this study. Correspondence and requests for materials should be addressed to Dan Kahan (dan.kahan@yale.edu). 


\section{References}

${ }^{1}$ Hart Research Associates, Report findings, http://www.nanotechproject.org/file download/files/HartReport.pdf (2006).

${ }^{2}$ Hart Research Associates, Awareness of and attitudes toward nanotechnology and federal regulatory agencies, http://www.nanotechproject.org/process/files/5888/hart_nanopoll_2007.pdf (2007).

${ }^{3}$ Macoubrie, J, Nanotechnology: Public concerns, reasoning and trust in government. Pub. Understanding Sci., 15(2), 221-241 (2006).

${ }^{4}$ Cobb, M. D., \& Macoubrie, J, Public perceptions about nanotechnology: Risks, benefits and trust. J. Nanoparticle Res., 6, 395-404 (2004).

${ }^{5}$ Scheufele, D. A., \& Lewenstein, B. V., The public and nanotechnology: How citizens make sense of emerging technologies. J. Nanoparticle Res., 7(6), 659-667 (2005).

${ }^{6}$ Scheufele, D. A., Five lessons in nano outreach. Materials Today, 9(5), 64-64 (2006).

${ }^{7}$ DiMaggio, P., Culture and cognition. Annual Rev. Sociology, 23, 263-287 (1997).

${ }^{8}$ Wildavsky, A., \& Dake, K., Theories of risk perception: Who fears what and why? Daedalus, 114, 41 (1990).

${ }^{9}$ Douglas, M., Purity and danger: An analysis of concepts of pollution and taboo (1966).

${ }^{10}$ Gutierrez, R., \& Giner-Sorolla, R., Anger, disgust, and presumption of harm as reactions to taboo-breaking behaviors. Emotion, 7(4), 853-868 (2007).

${ }^{11}$ Dake, K., Orienting dispositions in the perception of risk: An analysis of contemporary worldviews and cultural biases. J. Cross-Cultural Psychol., 22, 61 (1991).

${ }^{12}$ Douglas, M., \& Wildavsky, A. B., Risk and culture: An essay on the selection of technical and environmental dangers. Berkeley: University of California Press (1982).

${ }^{13}$ Peters, E., \& Slovic, P., The role of affect and worldviews as orienting dispositions in the perception and acceptance of nuclear power. J. Applied Social Psychol., 26(16), 1427-1453 (1996).

${ }^{14}$ Leiserowitz, A. A., American risk perceptions: Is climate change dangerous? Risk Analysis, 25(6), 1433-1442 (2005).

${ }^{15}$ Finucane, M. L., Mad cows, mad corn and mad communities: The role of socio-cultural factors in the perceived risk of genetically-modified food. Proceedings Nutrition Soc'y, 61(1), 31-37 (2002).

${ }^{16}$ Gelman, A., \& Hill, J., Data analysis using regression and multilevel/hierarchical models. Cambridge ; New York: Cambridge University Press (2007).

${ }^{17}$ Lord, C. G., Ross, L., \& Lepper, M. R., Biased assimilation and attitude polarization: Effects of prior theories on subsequently considered evidence. J. Personality \& Social Psychol., 37(11), 2098-2109 (1979).

${ }^{18}$ Kahan, D. M., Braman, D., Gastil, J., Slovic, P., \& Mertz, C. K., Culture and identity-protective cognition: Explaining the white-male effect in risk perception. J. Empirical Legal Studies, 4(3), 465-505 (2007). 
${ }^{19}$ Curall, S. C., King, E. B., Lane, N., Madera, J., \& Turner, S., What drives public acceptance of nanotechnology? Nature Nanotechnology, 1, 153-155 (2006).

${ }^{20}$ Mutz, D. C., \& Martin, P. S., Facilitating communication across lines of political difference: The role of mass media. Am. Pol. Sci. Rev., 95(1), 97-114 (2001).

${ }^{21}$ Cohen, G. L., Bastardi, A., Sherman, D. K., Hsu, L., McGoey, M., \& Ross, L., Bridging the partisan divide: Selfaffirmation reduces ideological closed-mindedness and inflexibility in negotiation. J. Personality \& Social Psychol., 93(3), 415-430 (2007).

${ }^{22}$ Kahan, D. M., Slovic, P., Braman, D., \& Gastil, J., Fear of democracy: A cultural critique of Sunstein on risk. Harv. L. Rev., 119, 1071-1109 (2006).

${ }^{23}$ Erika M. Edwards J. Michael Dennis Sergei Rodkin Ralph W. Hingson David L. Rosenbloom Timothy Heeren, A comparison of results from an alcohol survey of a prerecruited internet panel and the national epidemiologic survey on alcohol and related conditions, Alcoholism: Clinical \& Experimental Res. 32, 222-229 (2008).

${ }^{24}$ Miller, J. D., Scott, E. C., \& Okamoto, S., Science communication: Public acceptance of evolution. Science, 313, 765-766 (2006), supporting on-line material, http://www.sciencemag.org/cgi/data/313/5788/765/DC1/1.

${ }^{25}$ Chang, L. \& Krosnick, J., Comparing oral interviewing with self-administered computerized questionnaires: an experiment, http://communication.stanford.edu/faculty/Krosnick/Tel\%20Int\%20Mode\%20Experiment.pdf (under review).

${ }^{26}$ Peters, E. M., Burraston, B., \& Mertz, C. K., An emotion-based model of risk perception and stigma susceptibility: cognitive appraisals of emotion, affective reactivity, worldviews, and risk perceptions in the generation of technological stigma. Risk Analysis, 24(5), 1349-1367 (2004).

${ }^{27}$ Douglas, M., Natural symbols: explorations in cosmology. London,: Barrie \& Rockliff the Cresset P (1970).

${ }^{28}$ Flynn, J., Slovic, P., \& Mertz, C. K., Gender, race, and perception of environmental health risk. Risk Analysis, 14(6), 1101-1108 (1994).

${ }^{29}$ Satterfield, T. A., Mertz, C. K., \& Slovic, P., Discrimination, vulnerability, and justice in the face of risk. Risk Analysis, 24(1), 115-129 (2004). 